\title{
Article \\ Characteristics of changes occurring on the surface of thin-walled elements as a result of spot welding
}

\author{
Marzena M. Lachowicz ${ }^{1 *}$, Maciej B. Lachowicz ${ }^{2}$ \\ ${ }^{1}$ Wrocław University of Science and Technology, Poland \\ ${ }^{2}$ Machinefish Materials \& Technologies \\ Maciej B. Lachowicz, Ph.D.; lachowicz@machinefish.pl; \\ * Correspondence: Marzena Lachowicz, Ph.D.; marzena.lachowicz@pwr.edu.pl
}

Received: 30.04.2019; Accepted: 29.07.2019

\begin{abstract}
The paper presents the results of metallographic examination of a sleeve from a refrigeration system used in the food industry. On its outer surface, local surface changes were observed. Metallographic and microscopic SEM examinations were performed. It was found that the direct cause of their formation was the use of spot welding to regenerate its inner surface. It led to plastic deformation of the external surface as well as the formation of a layer of oxides with wustite properties.
\end{abstract}

Keywords: surfacing; regeneration of machine parts; welding distortions; chromium coating; metallography

\section{Introduction}

Parts of machines often work under high mechanical loads, fatigue processes or tribological wear. Therefore, the wear of machine parts is a natural process related to their operation. If there is a need to carry out repairs to ensure service life, the purchase of a new part in many cases is associated with high costs. In the case of atypical and unitary parts, creating a new element is often very difficult, and the waiting time for a new element would be associated with significant downtime costs. In such cases, it is economically justified to repair or modify existing components for which surfacing is successfully used. This allows, in a relatively short time and with low financial outlays, to restore the functional properties of damaged elements, and thus increase the service life of the regenerated machine. Regenerative surfacing has been used in particular to remove defects with small geometrical dimensions, such as corrosion pits, surface scratches or chips $[1 \div 5]$. It can also be used to repair defects arising at the casting stage $[2,6]$. The use of wear-resistant padding welds in the welding of machine parts allows to significantly extend the life of remanufactured elements [7]. The TIG or MIG/MAG methods are classically used in regeneration. However, laser methods can also be used [8].

The high temperature of the surfacing process and the accompanying phase transitions are associated with the formation of thermal and microstructural deformations. This leads to significant residual stresses. Issues related to modeling the temperature and stress distribution of welded elements and thin-walled welded elements, in their research were dealt with by the authors of works $[1,2,9 \div 11]$. The surfacing also leads to changes in the surface morphology of the surfacing area. This requires mechanical treatment of the surface. Often, the regeneration supplement carried out for the purpose of additional refining of the element or the dimensional change of the regenerated element is chromium plating. The main reason for using chromium coatings for this is their high hardness, wear resistance and low friction coefficient in most operating conditions [12].

The results presented in the work are intended to draw attention to the fact that surfacing of thin-walled elements can also lead to the formation of local changes observed on the surface opposite to the surfaced one. The resulting dimensional changes may be important especially when the surface works with other elements.

\section{Material and research methodology}

The subject of the research was a fragment of a cylindrical sleeve with a wall thickness of $5 \mathrm{~mm}$, which was part of the ammonia refrigeration device used in the dairy industry. On its internal surface, macroscopic morphology was observed, showing typical features of chromium coatings. The outer surface was characterized by the presence of numerous changes occurring in the form of a dark spherical tarnish (Fig. 
1). The outer plane of the tested sleeve cooperated with the second sleeve covered with a chrome coating. The space between them was filled with ammonia as a refrigerant. The presence of changes was observed at the stage of operation, when as a result of mechanical damage on the other of the sleeves it was perforated and refrigerant leaked.

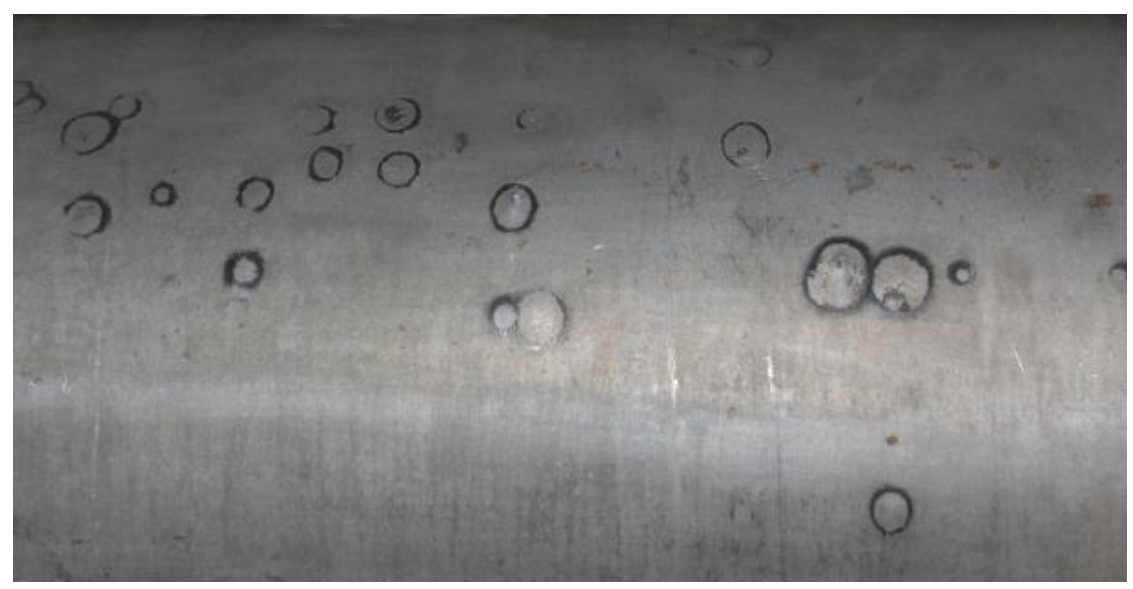

Fig. 1. General view of the outer surface of the sleeve. Visible damage in the form of a spherical tarnish

Photographic documentation of macroscopic examinations was made with a Nikon D3200 digital camera and Leica M205C stereoscopic microscope. Visual tests were carried out in accordance with PN-EN 13018. The microscopic tests were carried out using the Leica DM 6000M light microscope and the Phenom World Pro X scanning electron microscope. The chemical composition was determined by the spectral method using a LECO GDS-500A glow discharge spectrometer.

\section{Research results}

\section{Macroscopic examinations}

Macroscopic examination of the outer surface at the place of surface changes in the form of a dark tarnish showed the presence of slight protrusions of the surface arranged in such a way that the resulting tarnish was on their periphery. It was characterized by specific surface cracking. In the areas of convexity, mechanical micro-damage of the surface was also found, mainly in the form of scratches (Fig. 2 and Fig. 3).

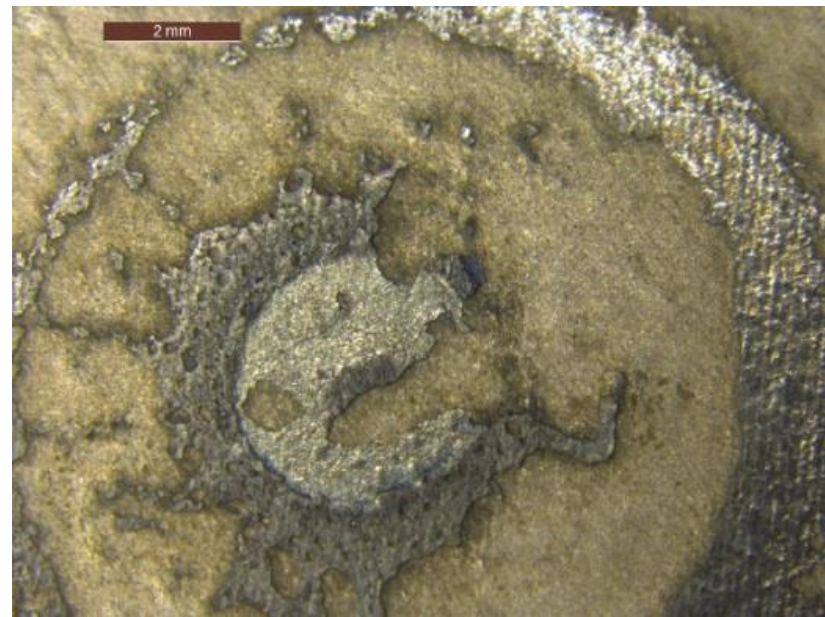

(a)

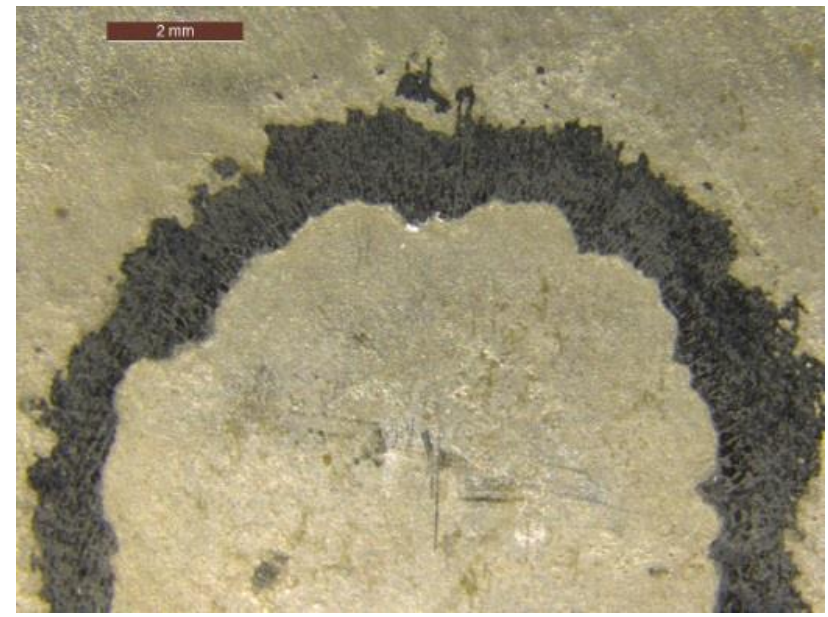

(b)

Fig. 2. Exemplary stereoscopic images of tarnish formed on the external surface: a) tarnish present in the central part of the convexity, b) tarnish present only on its periphery

\section{Metallographic examinations}

Microscopic observations were made on non-etched specimens made on the longitudinal section of samples taken through the tarnished area. It was found that the chromium coating on the inner surface of the sleeve was $0.35 \mathrm{~mm}$ thick. The occurrence of bulges on its outer surface was also confirmed (Fig. 4). Tests carried out after etching the samples with $5 \%$ nital showed that at the location of the tarnish and 
protuberances on the outer surface, there were changes in the macro- and microstructure of the tested material, indicating the surfacing of the pipe from its inside for regeneration (Fig. 5 and Fig. 6). The chromium coating on the inner surface was applied after regenerative surfacing of the sleeve.

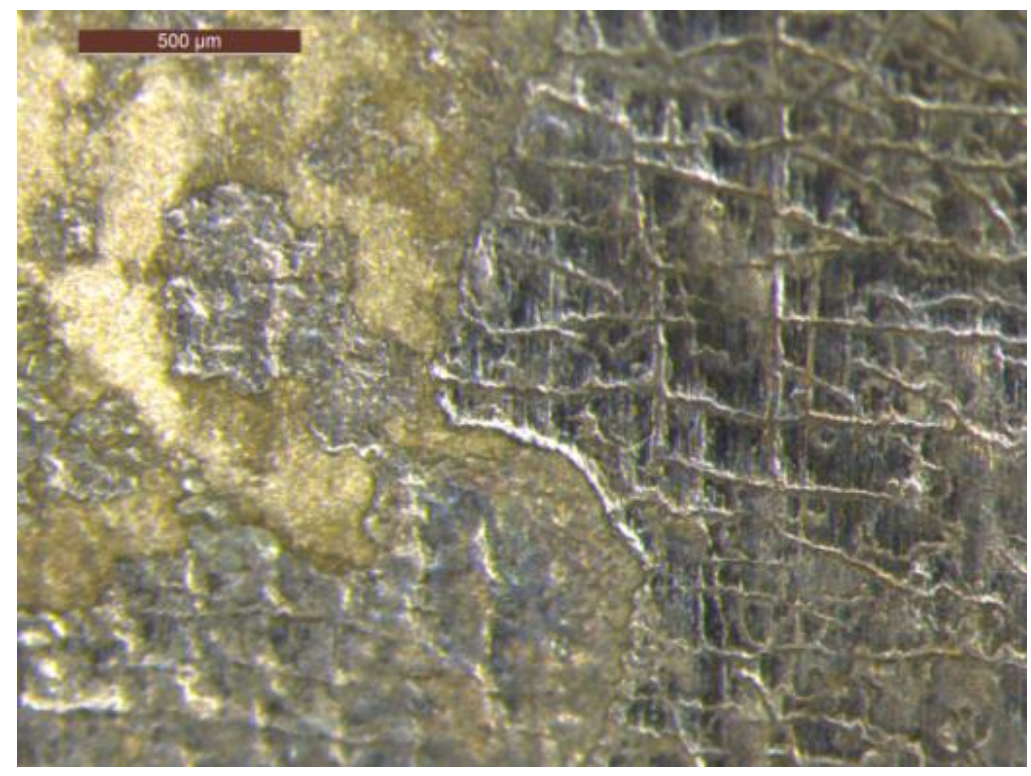

Fig. 3. An enlarged fragment of the tarnish formed on the outer surface. Visible its characteristic cracking. Stereoscopic microscopy

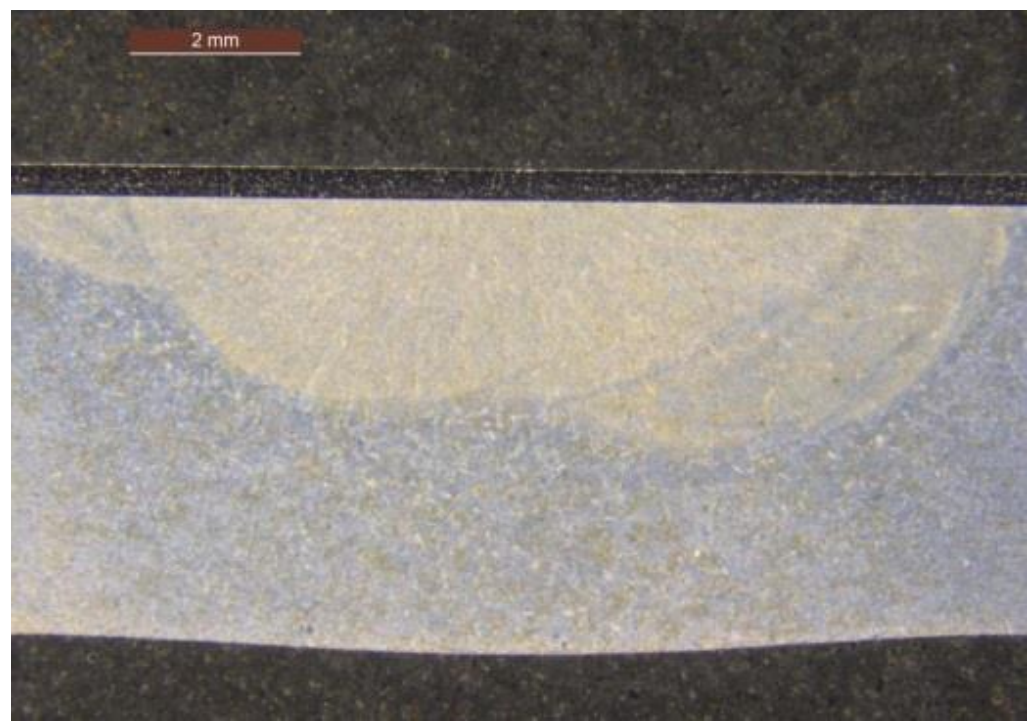

Fig. 4. Macroscopic image of the longitudinal section made by the sleeve. In the surface area from the inside there are visible further remelting beads and the applied chromium coating, while on the outside side the increase of the section's thickness. Stereoscopic microscopy

Subsequent thermal cycles affected the multiple phase changes occurring in the surfaced area, which led to the diversity of the material microstructure and promotes the formation of a complex state of stress and deformation in the weld. The microstructure of the native material was characterized by the occurrence of a ferritic-pearlitic structure with features of the Widmanstätten's structure. Structures characteristic for welded areas subject to recrystallization processes were observed in the heat affected zone (Fig. 5). In the surface area from the external surface side, the occurrence of local decarburization zones of the element with local grain growth that was not associated with surfacing was revealed (Fig. 6a). At a short distance from the surface, a microstructure typical for materials hardened as a result of rapid cooling, with local precipitation of upper bainite was observed (Fig. 6b).

As a result of the tests, it was found that the direct reason for the appearance of the protuberance on the external surface of the element was the use of spot welding. This was accompanied by local intensive heating of the material, uneven temperature distribution and shrinkage of solidifying metal. This translates into the formation of significant stresses, which are the result of thermal and structural deformations 
resulting from phase changes, as well as the plastic deformations of the areas surrounding the weld during subsequent thermal cycles. Winczek [1] showed that the residual stress in the area outside the heat affected zone is characterized by a linear distribution in relation to the section height, and in the case of the bottom surface of the welded element tensile stress dominates. He also stated that the highest values of plastic deformations are observed in areas with a significant share of bainite.

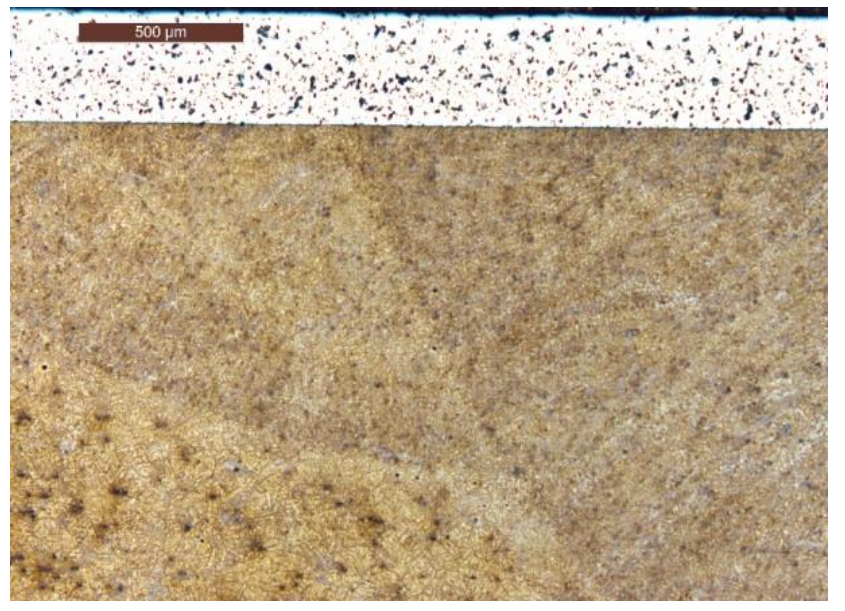

(a)

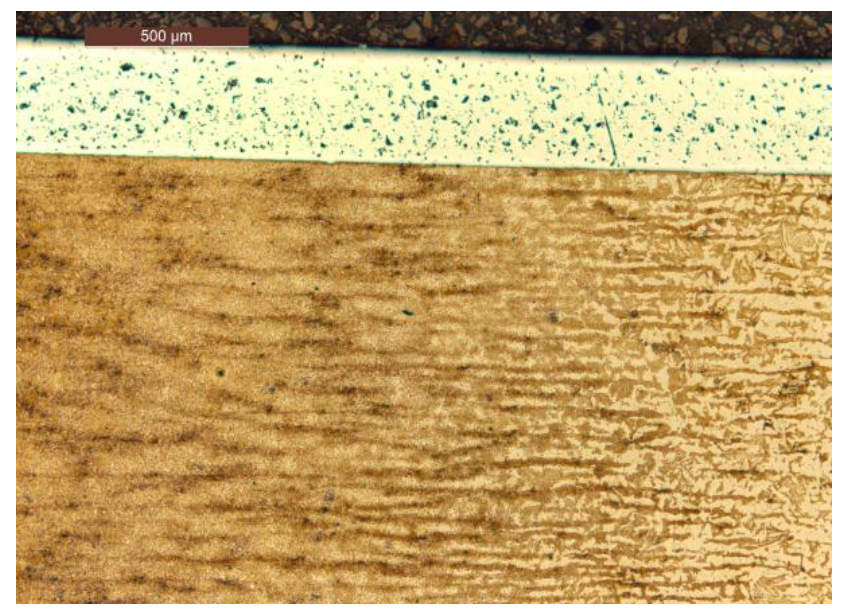

(b)

Fig. 5. Microstructure of the sleeve in the area of the inner surface: a) visible remelting beads and change of microstructure caused by thermal cycles. A visible chrome coating of $0.35 \mathrm{~mm}$ thickness on the surface; b) differentiation of the microstructure in the area of the heat affected zone (left) and native material (right). Light microscopy, etched state

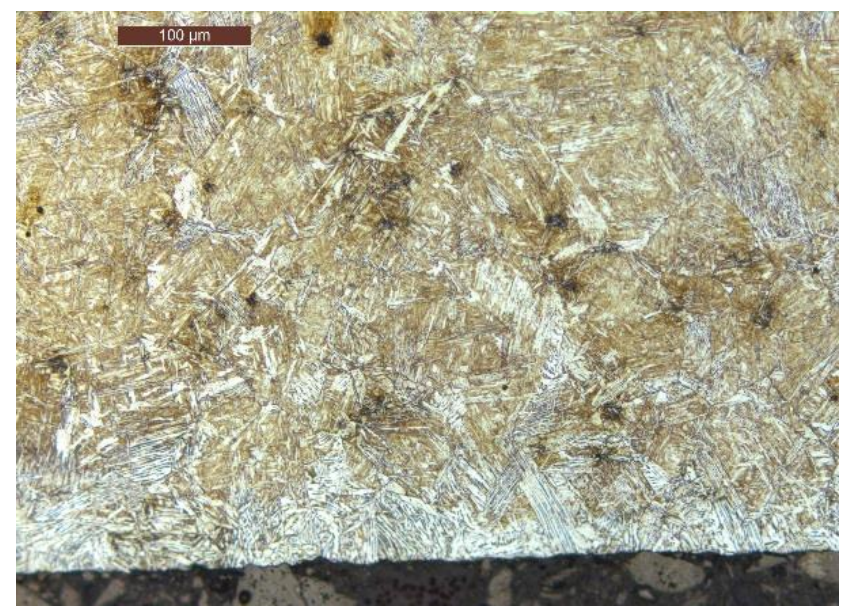

(a)

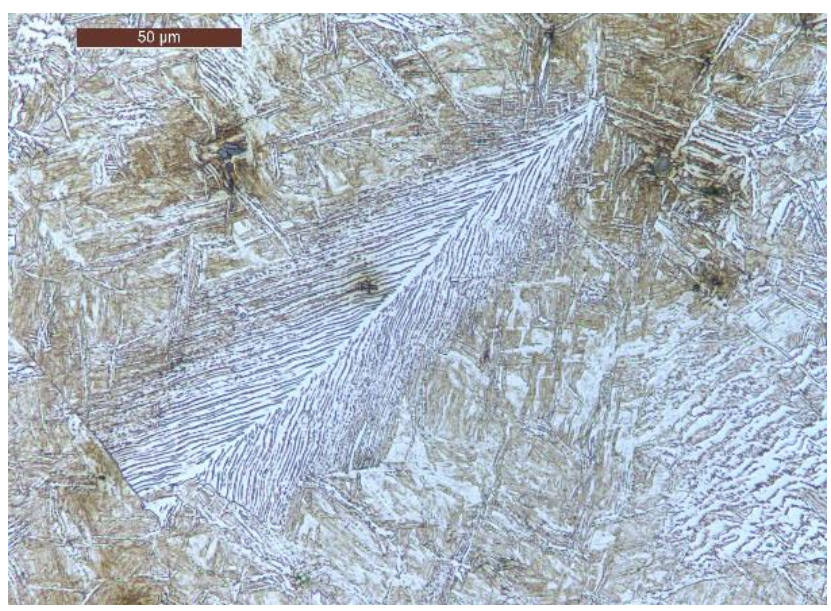

(b)

Fig. 6. Microstructure of the material in the near-surface area from the outside of the sleeve: a) visible microstructure exhibiting the features of decarburization and non-equilibrium cooling; b) locally visible bainitic microstructure. Light microscopy, etched state

\section{SEM microscopic examinations of the outer surface}

SEM microscopic examinations of the outer surface of the supplied fragment of the sleeve were carried out at the place where the characteristic dark tarnish occurred. As a result, it was found that it is mainly composed of iron oxides (Fig. 7, Fig. 8). Macroscopically, they were characterized by unusual coloring for brown corrosion products (rust) formed in aqueous corrosive environments, which color is mainly given by iron oxide $\mathrm{Fe}_{2} \mathrm{O}_{3}$ (Fig. 2, Fig. 3). This dark color has a wustite (FeO) in which iron is present in oxidation state II. Its creation indicates that during the surfacing of steel with the simultaneous influence of an oxidizing atmosphere, the temperature in the outer part of the sleeve had to exceed $570{ }^{\circ} \mathrm{C}$. The presence of an oxide layer was found not only in the spherically distributed tarnish on the surface, but also

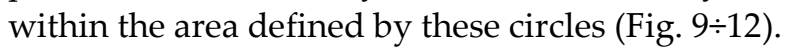

In areas where the formed oxides formed a layer spherically distributed around the circumference of the protuberances, a characteristic morphology was observed, formed by lines crossing at a right angle (Fig. 3, Fig. 7). Such specific cracking of the iron oxide layer on the surface was caused by their significant 
brittleness and tensile stress caused by a plane state of stress generated in the oxide layer. The stresses result on the one hand from different coefficients of thermal expansion of the base metal and this oxide layer, and on the other from welding deformations. A similar nature of cracks caused by residual stress is

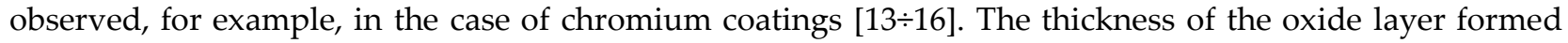
will depend on the temperature and duration of exposure to the oxidizing atmosphere. Most likely, originally the entire area of induced protuberance was covered with this scale, but they were removed from the surface of the element at the place of protrusion due to mechanical interactions and their chipping. These assumptions confirm the spallings observed in the microscopic image (Fig. 7a). With high probability it can be assumed that in this area there was an increased thickness of this layer, which was conducive to reducing its adhesion to the substrate. This eventually led to the creation of a shallow depression in this area.

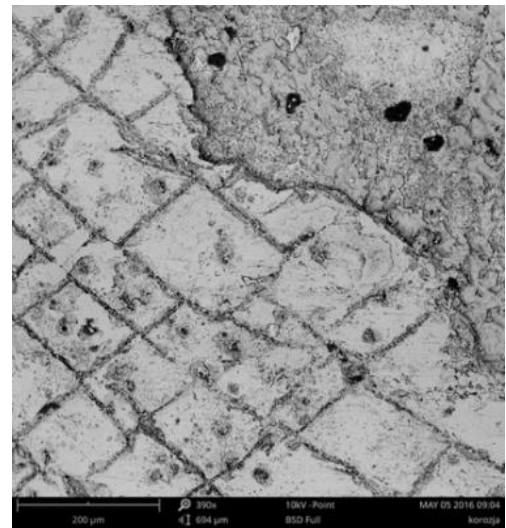

(a)

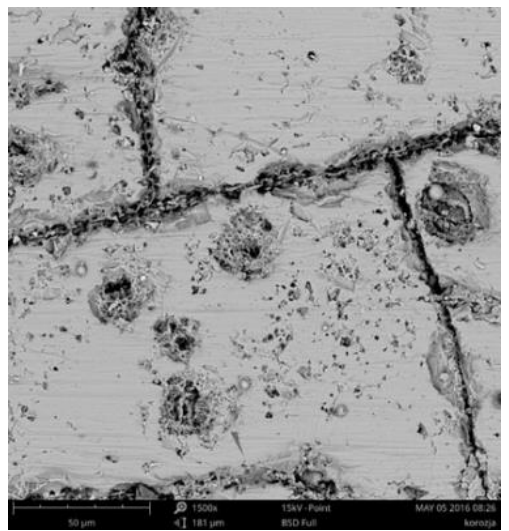

(b)

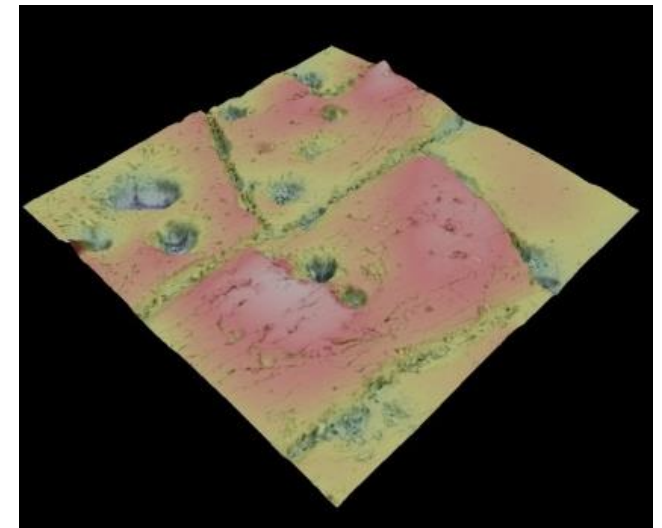

(c)

Fig. 7. The oxide layer formed on the perimeter of the convexity formed on the outer surface as a result of surfacing: a) visible characteristic cracking of the oxide layer and its mechanical spalling; b) enlarged fragment of the oxide layer; c) topographical 3D image of a fragment of the oxide layer's cracks. SEM



Fig. 8. The characteristic $X$-ray spectrum obtained from the area shown in Figure $7 \mathrm{~b}$ indicating the formation of oxide layers in this area

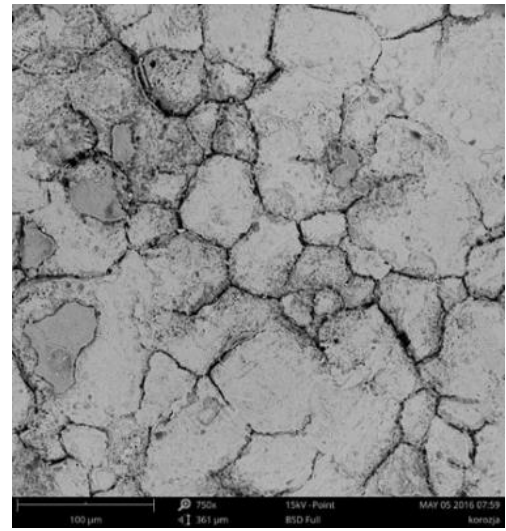

(a)

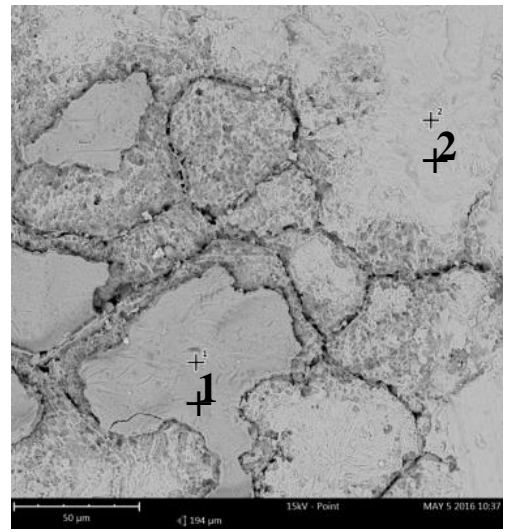

(b)



(c)

Fig. 9. Microscopic image obtained from the area located in the central part of the spherical tarnish: a) visible oxidation of the grain boundaries and the remains of the unchipped layer of oxides; $b$ ) enlarged fragment of the area from Figure a. Points 1 and 2 indicate the locations of the microanalysis of the chemical composition; c) topographical 3D image of a fragment of the oxidation boundary area. SEM 
Locally, in the surroundings of oxidation products, changes in the substrate material were observed, which indicated grain boundary dissolution (Fig. 9). Taking this into account, this sample was tested on the longitudinal section, which excluded the occurrence of stress corrosion. It was found that the observed changes located in the central part of the bulge, and thus in the area of temperature increase to the highest values, are associated with oxidation progressing along the grain boundaries. The remains of the oxide layer observed in these areas also confirm earlier assumptions about the presence of the oxide layer also inside the protuberance of the surface formed on the opposite side to the surfaced area (Fig. 9, Fig. 11). An example spectrum of the characteristic radiation obtained from the degenerated oxide layer is shown in Figure 10a, while from the substrate material in Figure 10b. There are significant differences in the intensity of oxygen reflections. The next stages of changes occurring on the outer surface of the tested sleeve are shown in Figure 12.



(a)

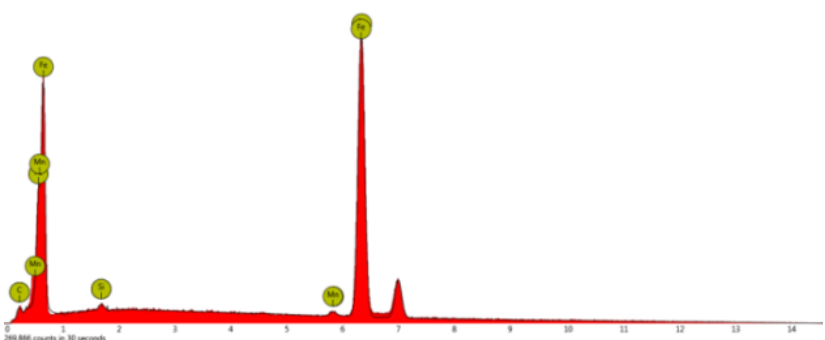

(b)

Fig. 10. The characteristic X-ray spectrum obtained from the points indicated in Figure 9: a) point 1 - indicating the presence of residues of the oxide layer formed during the surface deposition on the opposite surface; b) point 2 - in the area of the substrate material

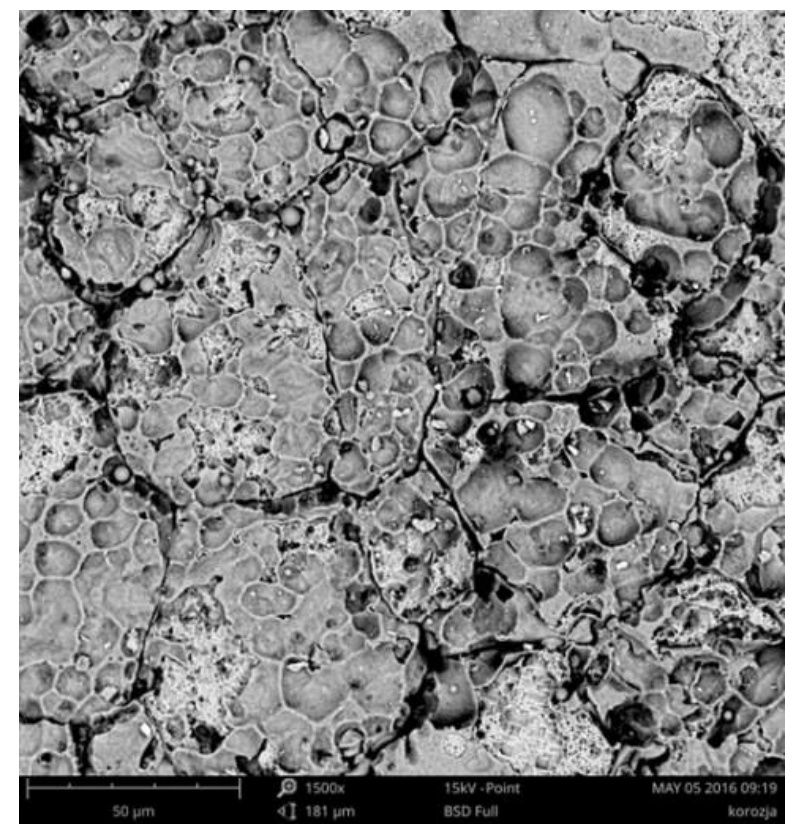

Fig. 11. Microscopic image obtained from the area of oxidation of grain boundaries. The visible layer of oxides formed on the surface. SEM

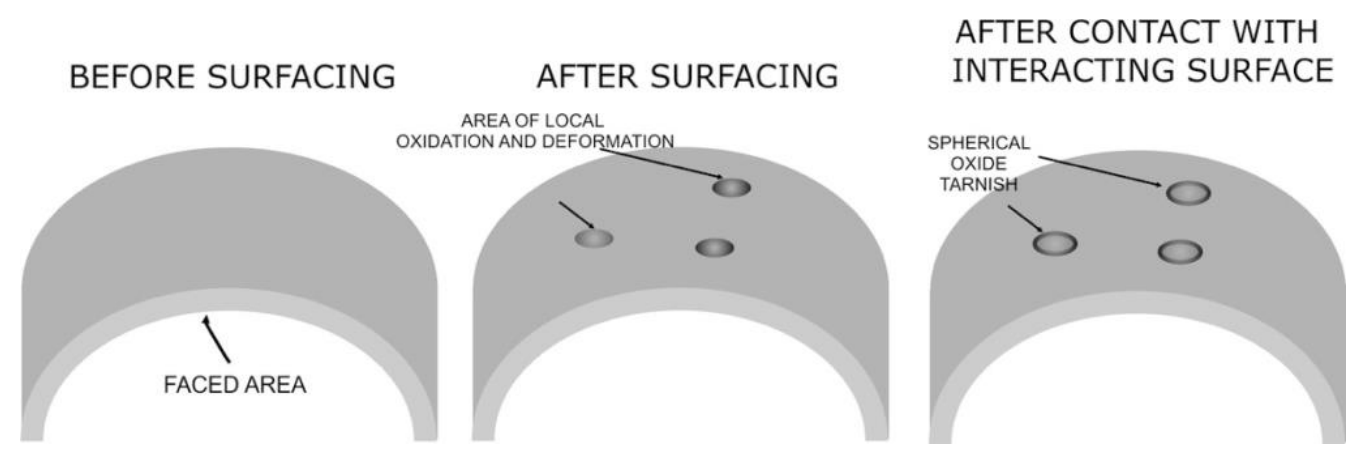

Fig. 12. Diagram of the formation of a spherical tarnish on the outer surface of the sleeve 


\section{Chemical composition analysis}

The chemical composition of the tested material is summarized in table I. It was found that the tested material in terms of chemical composition was consistent with structural steel grade S355JR according to EN 10025-2 (formerly 18G2A). However, it should be remembered that for these steels the determination of the chemical composition is not a sufficient criterion to confirm its compliance with the grade.

Table I. Results of the analysis of the chemical composition of the tested sleeve

\begin{tabular}{ccccccc}
\hline Element [\% mass] & $\mathbf{C}$ & $\mathbf{M n}$ & $\mathbf{P}$ & $\mathbf{S}$ & $\mathbf{S i}$ & $\mathbf{C u}$ \\
\hline Tested material & 0.20 & 1.38 & 0.020 & 0.020 & 0.20 & 0.06 \\
Requirements for S355]R steel & Max. 0.22 & Max. 1.6 & Max. 0.03 & Max. 0.03 & Max. 0.55 & Max. 0.55 \\
\hline
\end{tabular}

\section{Summary}

The presence of plastic deformations leading to the formation of surface bulges and dark oxide layers on the outer surface of the tested sleeve was associated with its point surfacing of the inner surface. The macro- and microstructure of the tested element, observed in the places of dark-colored spherical tarnish, testify to the use of surfacing for its regeneration. After the surfacing, the surface of the sleeve was covered with a chrome coating.

The formation of protrusions is associated with local heating occurring during the surfacing, which caused the formation of plastic deformations on the outer part of the sleeve. The formation of an oxide layer exhibiting the scale characteristics is associated with the thermal oxidation of heat affected zones located in the area opposite to the surfacing. The oxide layer is characterized by the dark color typical of the wustite $(\mathrm{FeO})$ and spherical distribution on the outer surface of this sleeve.

Their nature indicates that they originally covered the entire bulge area on the outer surface of the sleeve caused by microstructural changes, but due to mechanical contact with another element of the installation, their chipping took place and the area of their occurrence was limited to the envelope around the existing bulge. In the case of cooperating elements, the ingress of brittle oxides, as well as the formation of unevenness on the surface of one of them, may contribute to damage to its counter-surfaces. However, this depends on the nature of the work of this element and therefore each case should be considered individually.

A characteristic cracking of the oxide layer was found, characterized by the presence of lines crossing at right angles. The reason for the formation of cracks was caused by different values of thermal expansion coefficients of the base metal and this oxide layer, as well as deformation of the steel substrate due to surfacing. This morphology was determined by the plane stress state generated in the oxide layer. It was observed that the central part of the formed oxide layer was distinguished by intercrystalline oxidation. Such selective oxidation occurred in the area predisposed to obtaining the highest temperature values.

Author Contributions: conceptualization M.M.L; methodology M.M.L and M.B.L; formal analysis M.M.L; investigation M.M.L; writing-original draft preparation M.M.L; writing-review M.B.L; visualization M.M.L; funding acquisition M.B.L.

Funding: The research was carried out at Machinefish Materials \& Technologies.

Conflicts of Interest: The authors declare no conflict of interest.

\section{References}

[1] Winczek J., The Analysis of thermomechanical states in multipass arc weld surfaced steel elements, Archives of Metallurgy and Materials, 2018, Vol. 63(4), 1615-1628. [CorssRef]

[2] Winczek J., Gucwa M., Makles K., Analysis of thermal cycles and phase transformations during multi-pass ARC weld surfacing of steel casts taking into account heat of the weld, Journal of Applied Mathematics and Computational Mechanics, 2018, Vol. 17(1), 89-100. [CorssRef]

[3] Białucki P., Derlukiewicz W., Pad welding in the regeneration of die for aluminum pressure casting, Welding Technology Review, 2011, Vol. 83(10), 44-49.

[4] Smoleńska H., Kończewicz W., Łabanowski J., Marine engine valves plasma hard-facing regeneration, Welding Technology Review, 2011, Vol. 83(9), 73-78. [CorssRef]

[5] Kolasa A., Sarnowski T., Cegielski P., Regeneration of worn out machine parts surfaces by automatic welding, Welding Technology Review, 2015, Vol. 87(1), 50-57. [CorssRef] 
[6] Wojciechowski W., Kowalski J.S., Welding techniques in foundry. Surfacing, Archives of Foundy Engineering, 2013, Vol. 13(1), 87-90.

[7] Idziak E., Szyszka R., Siennicki A., Turek B., Robotic welding of excavator buckets, Górnictwo i Geoinżynieria, 2007, Vol. 31(2), 253-265. [Hyperlink]

[8] Nowakowski Ł., Wijas M., Finishing surface after regeneration with laser cladding, Procedia Engineering, 2017, Vol. 192, 1012-1015. [CorssRef]

[9] Winczek J., New approach to modeling of temperature field in surfaced steel elements, International Journal of Heat and Mass Transfer 2011, Vol. 54(21-22), 4702-4709. [CorssRef]

[10] Winczek J., Skrzypczak T., Thermomechanical states in arc weld surfaced steel elements, Archives of Metallurgy and Materials, 2016, Vol. 61(3),1623-1634. [CorssRef]

[11] Kulawik A., Modeling of thermomechanical phenomena of welding process of steel pipe, Archives of Metallurgy and Materials, 2012, Vol. 57(4), 1229-1238.

[12] Fedrizzi L., Rossi S., Bellei F., Deflorian F., Wear-corrosion mechanism of hard chromium coatings, Wear, 2002, Vol. 253(11-12), 1173-1181. [CorssRef]

[13] Ranjbar K., Sababi M., Failure assessment of hard chrome coated rotors in the downhole drilling motors, Engineering Failure Analysis, 2012, Vol. 20, 147-155. [CorssRef]

[14] Lachowicz M.M., Lachowicz M.B., Analysis of corrosion causes of the chromium-nickel coating applied for protecting the actuator of piston rods, Journal of Machine Construction and Maintenance - Problemy Eksploatacji, 2017, Vol. 104(1), 103-107.

[15] Zhang H., Liu L., Bai J., Liu X., Corrosion behavior and microstructure of electrodeposited nano-layered Ni-Cr coatings, Thin Solid Films, 2015, Vol. 595, Part A, 36-40. [CorssRef]

[16] Sheibani Aghdam A., Allahkaram S.R, Mahdavi S., Corrosion and tribological behavior of Ni-Cr alloy coatings electrodeposited on low carbon steel in Cr (III)-Ni (II) bath, Surface and Coatings Technology, 2015, Vol. 281, 144-149. [CorssRef]

(C) 2019 by the authors. Submitted for possible open access publication under the terms and conditions of the Creative Commons Attribution (CC BY) license (http://creativecommons.org/licenses/by/4.0/). 